\title{
NEW APPROACH TO CREATE MORE EFFECTIVE TEAMS IN THE INNOVATION PROCESS IN ENTERPRISES
}

\author{
Ewa OKOŃ-HORODYŃSKA D, Anna ZACHOROWSKA-MAZURKIEWICZ D, \\ Rafał WISŁA (D), Tomasz SIEROTOWICZ (D) \\ Department of Economics and Innovation, Institute of Economics, \\ Finance and Management, Faculty of Management and Social Communication, \\ Jagiellonian University, Krakow, Poland
}

Received 24 September 2018, accepted 04 February 2020

\begin{abstract}
The subject-related literature provided information about the skills, education, and formal competencies required to join teams working on the innovation process. According to findings presented in this article, the previous studies have investigated insufficiently the gender-related issues in the decisions of managers who involve specialists in the innovation process. Thus, the purpose of this research was to identify, examine, and describe differences in the participation of men and women in the innovation process, considering their personal characteristics, attitudes, and behaviours. The research covered 1,164 innovative companies - beneficiaries of the European Union Cohesion Policy of 2007-2013. The survey was distributed independently to women and men participating in innovative activities in the researched companies. Two independent responses were received from each company; thus, two independent data samples were created. Both data composition and preliminary analysis adhere to the requirements of Principal Component Analysis. The results allow for the new design proposal to increase the effectiveness of teams working on innovation-focused tasks. In addition to education and experience, managers can now consider personal characteristics and better select women and men to drive innovation.
\end{abstract}

Keywords: innovation management, innovation development, gender research, creation effective teams, decision making in innovative activity, process of innovation, manage new source of innovation progress.

JEL Classification: O15, O31, O35, D91.

\section{Introduction}

Innovation is perceived as equivalent to the creation of something new or modified (Organisation for Economic Co-operation and Development [OECD], 2005). The processes of innovation and scientific research are not gender-neutral activities. Moreover, even if science, in its search for objectivity, tends to dismiss the dimension of gender, it is still deeply

*Corresponding author. E-mail tsierotowicz@uj.edu.pl

Copyright (C) 2020 The Author(s). Published by VGTU Press

This is an Open Access article distributed under the terms of the Creative Commons Attribution License (http://creativecommons. org/licenses/by/4.0/), which permits unrestricted use, distribution, and reproduction in any medium, provided the original author and source are credited. 
embedded in the presented approaches to studying science and developing new technologies. Thus, it influences the entire innovation process (Abels, 2012). Much of the research on the subject has provided insight about the skills and competencies required to join teams working in the innovation process. However, managers who choose specialists for their dedicated fields and competencies should also consider gender-related issues along with the personal characteristics, attitudes, and behaviours needed in the various phases of this process. Thus far, the main issue is the gender ratio of researchers which, if improved, could increase the effectiveness of teams working on innovation-focused tasks through a better selection of individuals in each phase of the process. Consequently, the following research questions arise: Are there gender-related differences between the various innovation processes undertaken in pioneering companies in Poland? If so, what is the appropriate way of characterising and describing them, apart from focussing on education and experience?

The unique features of women and men that influence the innovation process were identified and described. The purpose of the research, presented in this article, is to examine, identify, and describe the differences in the participation of men and women in the innovation process, taking into account their personal characteristics, attitudes, and behaviours directly in the environment of the innovative companies of Poland. The purpose of this paper is to present a literature review on the subject; a methodology, which includes descriptions of the conceptual framework of the research, data, and reasons for using the presented methods of analysis; and the next subchapter, which presents the analysis results. In this subchapter, female and male participation models in the innovation process are presented and described. The paper also provides a discussion on the obtained results, the conclusions derived from them, a future research proposal, and a list of references.

\section{Literature review}

As this research focuses on gender and the innovation process, it is worth beginning with the definitions of the main concepts. Innovations are defined in Schumpeter's (1934) classic definition, as new combinations of production factors, such as the production of new goods, introduction of new processes, opening of new markets, access to new sources of raw materials and intermediates, and the re-organisation of an industry. Therefore, the term innovation encompasses a range of aspects from product, service, process, position, strategic, and governance, to rhetorical propositions. Moreover, they may be revolutionary, radical, emergent, or incremental (Fogelberg, 2014; Demos \& Segal, 2017). As Amabile et al. (1996) stated, all innovations begin with creative ideas; successful implementation of new programmes, new product introductions, and new services all rely on the quality of that initial idea. In their opinion, creativity is the production of novel and useful ideas in any domain, and innovation is the successful implementation of creative ideas within an organisation (Amabile et al., 1996). Nevertheless, innovation cannot be reduced solely to considerations around creativity, as new ideas are merely the first step on the road to creating successful innovation (Foss et al., 2013). Innovation has gained increasing attention among researchers; however, cross-disciplinarily studies and the increasing number of publications on innovation, make it a difficult field to survey (Fogelberg, 2014). 
In this research, the focus was on one of the main aspects of innovation: the influence of diversity. Studies have suggested that diversity has a positive effect on innovation (Østergaard et al., 2011; Salk et al., 2017). The aspect of diversity of interest here is that of gender diversity. Several studies and reports have stressed the significant problem of the underrepresentation of women in the science and business sectors (Hunt et al., 2013; Ye et al., 2019). The results of international empirical comparative studies indicate that, in general, there is a clear statistical pattern that demonstrates women are less involved than men in the creation of scientific and industrial knowledge (Sierotowicz, 2015; Messerschmidt et al., 2018). These studies primarily concentrate on the representation of women and men in patent activity, while innovation literature has been criticised for not taking gender into account (Foss et al., 2013, p. 299).

Gender has not been a particularly prominent focus of innovation-based research (Alsos et al., 2013); the concept of gender and innovation has only recently gained a wider interest among researchers and one of the key reasons suggested for this, is the apparent invisibility of those in innovation (Alsos et al., 2013). It was observed that when people are not visible in the discourse, gender easily becomes forgotten (Alsos et al., 2013). Ranga and Etzkowitz (2010) pursued this argument further, claiming that innovation is not gender-blind but inherently gender-biased due to an implicit, socially constructed assumption that women are less innovative than men. They claim that this is a function of traditional gender-relations, rooted in the social perception that technology is associated more with men than women. Foss et al. (2013) assume that the process of innovation is gendered in such a way that masculine ideas are implemented to a greater degree than feminine ones. Following the argument that the likelihood of introducing innovation is greater in organisations in which a minority group has a critical mass to contribute to the innovation process (Østergaard et al., 2011), in a male-dominated organisation, gender has a moderating effect on the relationship between the generation of ideas and their implementation, because women employees encounter more obstacles (Foss et al., 2013). However, research has indicated that creative performance requires both masculine and feminine components (Foss et al., 2013) and a study by Østergaard et al. (2011) exposed a strong, positive, and significant relationship between gender diversity and innovation. The results of the study demonstrated that notably low or high levels of diversity are not significantly different from each other. Nevertheless, a moderate degree of diversity (in which a minority group has a critical mass to contribute to the innovation process) appears to have a higher likelihood of introducing innovation.

Alsos et al. (2013) noticed that the combination of adopting perspectives of gender (as a variable) and innovation (as a result) is likely the dominant approach in empirical research on gender and innovation. This perspective is reflected in studies of innovation in maleand female-owned businesses, as well as in the literature on gender differences in patenting and commercialisation in a university context. Foss et al. (2013) used gender as a variable in addressing the innovation process; they showed that women are equally as innovative in generating new ideas as men, but that their ideas are less frequently implemented within their organisations. The gender-dimension of innovation is usually considered a peripheral element of the process, which narrowly focuses on issues such as the inclusion or exclusion of women in research and development, or innovation. The role of women in innovation is often not perceived as an important part of the process, even when they are a key link in the 
chain (Ranga \& Etzkowitz, 2010). Cooper (2012) explained that women are not perceived as innovators, so their ideas are either not heard, or are deemed inferior to those of men's, therefore, they rarely proceed to the implementation phase. Alsos et al. (2013) concluded that this is not because women lack capability in innovation, but rather that organisational practices condition or inhibit women's innovative behaviour.

Amabile et al. (1996) assumed that social environment can influence both the level and frequency of creative behaviour; however, the pressure of work also influences creativity, and this influence can be either positive or negative. Research by Foss et al. (2013) establishes that work pressure has a positive effect on the generation of ideas. The gender-related context, when viewed alongside the relevant contemporary research, is broad; for example, Blake and Hanson (2005) argued that the social and geographical contexts of an innovation are elementary to its identification as being "innovative". They also noted how the numerous instances of innovation, occurring in economic sectors, are typically ignored or undervalued by current research (Blake \& Hanson, 2005; Abukhait et al., 2019). Danilda and Thorslund (2011) presented ways in which companies in Sweden and Norway seek to gain a competitive advantage through the integration of gender perspective in innovation work, as an example of the research related to the gender role in the culture of innovation within organisations (Ghaye \& Gunnarsson, 2009). One of the research topics conducted by Linberg and Schiffbaenker (2013) was that of gender issues in the innovation process: the research focused on difficulties that sometimes occur between women and men and how they can be overcome. They concluded that the differences in the approaches of women and men towards innovation could be resolved through policy and practice (Linberg \& Schiffbaenker, 2013).

In research relating specifically to the issue of gender and innovation, the topic of creative knowledge, as a crucial component of the knowledge economy, was at the forefront of the research (Lindberg et al., 2012). This research focused on network development, where both triple and quadruple helixes have the potential to enhance the diversity of actors (i.e. women and men) in the contexts of both the knowledge economy and innovativeness. It covered the three gender dimensions in innovation and gender-bias, initially conducted by Nählinder, Tillmar and Wigren (2015). The gender nature of the innovation process, in relation to ethnographic issues in terms of "positions and displacement", was studied by Pecis (2016, p. 2131), who argued that there is often a combination of both fluidity and messiness when it comes to the innovation practices of women and men. A much greater spectrum of research was provided by Pettersson (2007), who suggested that gender is related to innovation in a wider social field and in a variety of situations, not solely reserved for innovation processes conducted in innovative enterprises. Her research specifically related to policies and aimed at enhancing innovation from a gender perspective in three countries within the European Union: Denmark, Finland, and Sweden. Further research regarding gender positions within organisations and the invention processes was proposed by Poutanen and Kovalainen (2013); they argued that the gendering of innovative products can be caused by tokenism, which can also be interpreted as a deliberate, but successful process. However, this approach is difficult to sustain in profit-seeking organisations, such as innovative companies, where the real contribution of each person must be identifiable. 
The issue of gender relationships in a leadership context within innovative companies in India, was the subject of research by Reutzel, Collins and Belsito (2018). Dyląg and Szafrański focused their research on personal qualities and values compartmentalised by gender (2015). They concluded that women and men share certain values, such as self-respect, health, and honesty; however, they also recognised that there exist differences between them. For example, women value meaning in life, while men point at inner harmony; interestingly, men indicated values that are considered least important by women, namely social power, authority, and sacrifice. In relation to innovativeness, there were no statistically significant differences between men and women, not only in creativity, but also in values such as curiosity and openness to change. The different roles and positions of women in society could determine their innovative activity (Carrasco, 2014); as mentioned previously, personal attitudes also play important roles in innovative activities. Female managers utilise a collaborative and cooperative approach when leading organisations, and female business owners have a stronger preference for collaborative networking than their male counterparts (Foss et al., 2013). It was also apparent that "competition" was often associated with the male element of the innovation process, while women were viewed more as "consensus builders" (Ranga \& Etzkowitz, 2010; Du Vall \& Majorek, 2015; Kopycinska, 2015; Zachorowska-Mazurkiewicz, 2016).

The literature presented supplies a wealth of valuable knowledge concerning gender and innovation. All the areas of research mentioned above, have the potential to influence the innovative activities by the women and men involved in the innovation process. Furthermore, researchers such as Danilda and Thorslund (2011), Blake and Hanson (2005), and Pecis (2016) all indicate that the object of research in gender and innovation is dependent on the geographical and social environments. More succinctly, the examined object is open to change and differences between countries (Dufwenberg \& Muren, 2006; Apesteguia et al., 2012). Thus, research provided from the perspective of gender in the innovation process, conducted in Polish innovative companies, will provide new knowledge on the matter. Innovation processes are always organised into projects, as such, personal characteristics should support the creation of more effective teams working at different stages of the innovation process. This is the view held by the main research described in this article, and it is an unfamiliar stance, even for contemporary researchers. Innovation is also related to entrepreneurship, an ideal where the obstacle of work and family-life balance is expected to hinder women's innovative activities. Thus, it could be assumed that the more institutions help to balance the scales of family and work, the more women will become engaged in innovation (Brieger \& Francoeur, 2019; Kunze \& Miller, 2017).

In order to achieve the research objective presented in the introduction, the following hypotheses were formulated: the process of innovation is not gender neutral (H1); profiles of men and women in the innovation process can be described using specific characteristics, behaviours, skills, and roles (H2); moreover, these specific characteristics, behaviours, skills, and roles are different for men and women. In order to verify these hypotheses, the research is comprised of only innovative companies, where at least one innovation process took place during a specified period. For this reason, the research covers 1,164 Polish innovative companies, all of which were beneficiaries of the EU Cohesion Policy 2007-2013. Participation in the EU Cohesion Policy program ensures that the companies in this research were innovative. 


\section{Method}

\subsection{Conceptual framework and preparation of survey}

The literature related to innovation suggests of 4, 5 and 6 stages of innovation processes (Tidd \& Besant, 2017; Geissdoerfer et al., 2016; Skarzynski \& Gibson, 2013; Acklin, 2010; Twiss, 1995: Rothwell, 1994). In order to achieve the main objective, and based on the stages of innovation processes presented in the literature, a fresh process of innovation was created. It comprised of the six basic stages of the innovation process: (1) creativity (generating of ideas); (2) accumulation (idea accumulation and protection); (3) prioritisation (choosing of ideas to be implemented); (4) development (testing and preliminary assessment of possibilities to commercialise ideas); (5) potential innovation (ready solution, preparation of commercialisation strategy, market research, pricing); and (6) innovation (implementation of a new or improved solution, first financial rewards). At each stage of the innovation process, the following five socio-psychological areas were applied: (1) work environment, (2) personal attitudes, (3) personal qualities, (4) values and behaviours, and (5) roles in the team. Finally, each socio-psychological area consists of five variables applied separately for men and women in an open innovation environment. This equates to a total of 25 variables used to construct the questionnaire to fulfil the purposes of this study. This conceptual framework will enable the research to ascertain the significance of all 25 variables at each stage of the innovation process, and each of the five socio-psychological areas. These 25 variables describe are the most common personal characteristics observed in the attitudes and behaviours of men and women. At the beginning of the research, the conceptual framework is an unverified starting point; however, it will be empirically verified and modified, based on the analysis and results of the research. Both the assigned socio-psychological areas and the total variables were subject to change, separately for women and men, according to obtained results; thus, the conceptual framework played only an initial role in the research process. After empirical verification, the models of the participation of women and men in the innovation process are designed.

\subsection{Data}

In order to achieve the objective and verify the hypotheses of $\mathrm{H} 1$ and $\mathrm{H} 2$, the research covers only innovative companies, where at least one innovation process took place during a designated period. For this reason, the research comprises 1,164 Polish innovative companies, which formed the entire population of beneficiaries of the EU Cohesion Policy 2007-2013. Participation in the EU Cohesion Policy program ensures that companies involved in this research were innovative.

The survey was made available online to male and female respondents, employed in these enterprises and involved at various stages of the innovation process, between 15 October and 15 December 2015. Respondents embodied a wide spectrum of roles, from team members to managerial positions. The questionnaire was distributed independently to male and female employees, ensuring that each company was represented by one male and one female employee involved in the innovation process. As a result, two independent samples of data were created. 
In addition to gender, age, and education, each questionnaire contained questions relating to all 25 variables of the innovation process. Each variable represented a quality, attitude, or behaviour characterised by a single person (both women and men) that was involved in the innovation process of a participating company. Each question was presented as a five-point standard Likert scale, used in similar research, with the scales ranging from strongly disagree to strongly agree; this method allowed us to gauge the importance (i.e. Likert scale $1-5$ ) of the variables (quality, attitude, or behavior) at each stage of the innovation process. In each case, the scores summarised the answers in all six stages of the innovation process.

The 562 cases, collated from two independent groups of both women $(\mathrm{N}=283)$ and men $(\mathrm{N}=279)$, formed two independent data samples. In the group of women, whose ages ranged from $18-64$ years $(M=33, S D=7.7), 86 \%$ possessed higher education. In the group of men, whose ages ranged from $18-65$ years $(M=36, S D=9), 87 \%$ had higher education. The initial analysis of samples led to the conclusion that the samples were appropriate to use with an exploratory analysis method (Cattell, 1978; MacCallum et al., 1999; Henson \& Roberts, 2006; Hair et al., 2014).

The conducted research verified the 25 variables described in the conceptual framework. Achievement of the research goal was made possible by explaining, in a statistically significant way, the variance of each variable (not only shared variance). Moreover, the emergence of a set of groups of variables that act as carriers of the information, are the best explanation of the research object, and in which a loading value for each variable in the group explains the level of participation of women and men in the innovation process. Thus, the underlying questions related to method selection became apparent: what are the sets of variables, their loading values, and component structure that provide the statistically significant explanation of the research object? Do all variables describe significantly the research object? Such questions lead to the selection of the statistical method; this highlights the statistically significant sets of variables that are best equipped to describe the focus of the research. In order to use this method, the preliminary analysis must first be performed.

\subsection{Preliminary analysis}

In order to verify the model, SPSS 23 and Amos 23 were used. A Shapiro-Wilk's test ( $p>.05$ ) and a visual inspection of the histograms, normal Q-Q plots, and box plots showed that across all 25 variables tested, none of them - for neither women or men - were of even approximate normal distribution (Shapiro \& Wilk, 1965; Razali \& Wah, 2011). The result closest to normal distribution was identified in the female sample for the variable "negotiator", where the Shapiro-Wilk's test significance value was 0.019 , with a skewness of -0.207 $(\mathrm{SE}=0.145)$ and a kurtosis of $0.166(\mathrm{SE}=0.289)$ (Cramer, 1998; Cramer \& Howitt, 2004; Doane \& Seward, 2011). In conclusion, among the preliminary considerations, the sample data was not normally distributed; however, it was suitable for use with one of the exploratory analysis methods, such as Principal Component Analysis PCA. The subject literature noted that the research object is susceptible to change, according to geographical and social environment; in other words, the structure of variables used to describe the object of the research will also change. In such cases, the method allows the object to be described with 
more variables, and minimal loss of information is a better choice than a method providing a better estimate of the unchanged structure of the explored object (Snook \& Gorsuch, 1989; Kim, 2008; Hair et al., 2014). It for these reasons, that the PCA method was chosen over that of the Confirmatory Component Analysis CFA.

Of the 25 initial variables for the women's sample, 18 fulfilled the values of the parameters included in the PCA procedure. The visual inspection of the variable correlation matrix revealed numerous correlations above 0.3 and no variable with correlations below 0.3 . The determinant $(\mathrm{a}=0.001)$ fulfilled no multicollinearity condition $(\mathrm{a}>0.00001)$ (Field, 2012). The Kaiser-Meyer-Olkin Test $(\mathrm{KMO}=0.919)$ allowed the sample adequacy condition to be accepted (KMO > 0.6) (Kaiser, 1970; Kaiser et al., 1974; Hair et al., 2014), with anti-image correlation matrix diagonal values (MSA > 0.7) (Dziuban \& Shrinkey, 1974). The Bartlett's Test of Sphericity p-value (Sig = 0.000) fulfilled the significance condition $(\mathrm{p}<0.05)$ (Bartlett, 1950) and validated the PCA procedure for the female sample. The Kaiser criteria (Kaiser, 1960) (Eigenvalue $>1$ ), the Scree plot test (Cattell, 1966), and the Monte Carlo Parallel Analysis ( $\mathrm{p}<0.05$ for thousand permutations) of the data set for non-normally-distributed samples (O'Connor, 2000) revealed three components at the $54.28 \%$ of total variance explained, which is considered an acceptable result in the field of humanities (Pett et al., 2003; Hair et al., 2014).

Of the 25 initial variables of the male sample, 17 fulfilled the values of the parameters included in the PCA procedure. A KMO $=0.896$ showed the sample adequacy condition. The Bartlett's Test of Sphericity p-value (Sig $=0.000)$ fulfilled the significance condition and validated the PCA procedure for the male sample. The Kaiser criteria (Eigenvalue $>1$ ), the Scree plot test, and the Monte Carlo Parallel Analysis ( $\mathrm{p}<0.05$ for thousand permutations) of the data set for abnormally distributed samples, revealed four components at the $56.08 \%$ of total variance explained.

These results are evidence that the PCA with the Promax rotational method can be used to conduct research, achieve objectives, and verify hypotheses; however, PCA offers many configurations, one of which is the decision to select the rotational method. The PCA method also allows the selection of one of the orthogonal methods, such as Varimax (default), Equimax, and Quartimax, or one of the oblique methods, such as Oblimin, Promax, and Orthoblique. The pertinent question here is: should the factors be correlated (oblique) or uncorrelated (orthogonal)? "The choice of an orthogonal or oblique rotation should be made on the basis of the particular needs of a given research problem" (Hair et al., 2014, p. 114). In order to answer this question, it is necessary to describe the nature of the object of the research undertaken. The orthogonal methods are mostly commonly applied in physics, specifically electronics in digital signal and image processing (Smith, 2013; Alvarez et al., 2018). However, this research is devoted to human activity, which signifies a coherent unity and is also the most important when informal and hidden aspects of the human performance is characterised (Frankl, 1967, 1869). Thus, the nature of the examined object would suggest the use of an oblique method, the reasonable assumption being that the components could be correlated. In order to select the most appropriate rotation, both uncorrelated and correlated components were verified. Despite this assumption, use of the Promax rotation with Kaiser normalisation (Kline, 1994; Norman \& Streiner, 2003; Steiner et al., 2015; Dien et al., 2005) 
allowed the best results to be obtained. The application of the orthogonal or oblique method of analysis required a different interpretation of the results. Whereas, for the Promax rotation method and samples size 100 or larger, with the "practical significance as the criteria, can be accessed the loadings as follow:

- Factor loadings in the range of \pm .30 to \pm .40 are considered to meet the minimal level for interpretation of structure;

- Loadings \pm .50 or greater are considered practically significant;

- Loadings exceeding 1.70 are considered indicative of well-defined structure and are the goal of any factor analysis." (Hair et al., 2014, p. 115).

Applying the selected statistically significant variables and components provide further accuracy for the model developed in this study. Considering the nature of the research object and managerial point of view, the significant level of variable explanation represents sufficient accuracy. Both the conceptual research context and the preliminary analysis fulfilled the assumptions that informed the decision to use PCA (Costello \& Osborne, 2005; Zinbarg et al., 2006; Larsen \& Warne, 2010; Field, 2012); however, the nature of the research object suggested the use of the oblique rotation method. The results of the PCA method, combined with the use of the Promax rotation method, are presented in the following subchapters.

\section{Results}

As a result of the PCA procedure, two models were obtained (Figures 1 and 2), which considered the variables after empirical verification. The variables were grouped into three components for women and four for men: in each of the components, the values of the loadings indicated a statistically significant level of explanation of variance for each of the variables, describing the roles, attitudes, and competencies of women and men involved in the innovation process for the participating companies.

\subsection{Women participation models in innovation process}

In the model for women, seven variables were considered statistically insignificant: competition, workload, autonomy, perceptiveness, compliance to rules and regulations, ability to persuade, and representative. In the model for men, eight variables were considered insignificant: cooperation, competition, workload, perceptiveness, risk propensity, compliance to rules and regulations, calculating persona, and representative.

Figure 1 (model 1 ) presents the values of each variable loading in the designated component. The component loading value signifies the total variance explained for each variable included in the designated component (range 0-1). The components represent the variable groups of qualities, attitudes, and behaviours of women involved in the innovation process.

Based on the variables included in the components and their average loadings, the components were: professional attitudes, 0.645; roles in the team, 0.699; and personal qualities, 0.759 . These three components contain 18 variables out of the 25 variables covered in the research. These also represent a different, and empirically proven, design of the model of female participation in the innovation process in Polish innovative companies. Since these components contain different sets of variables, their names also differ and are more suited 


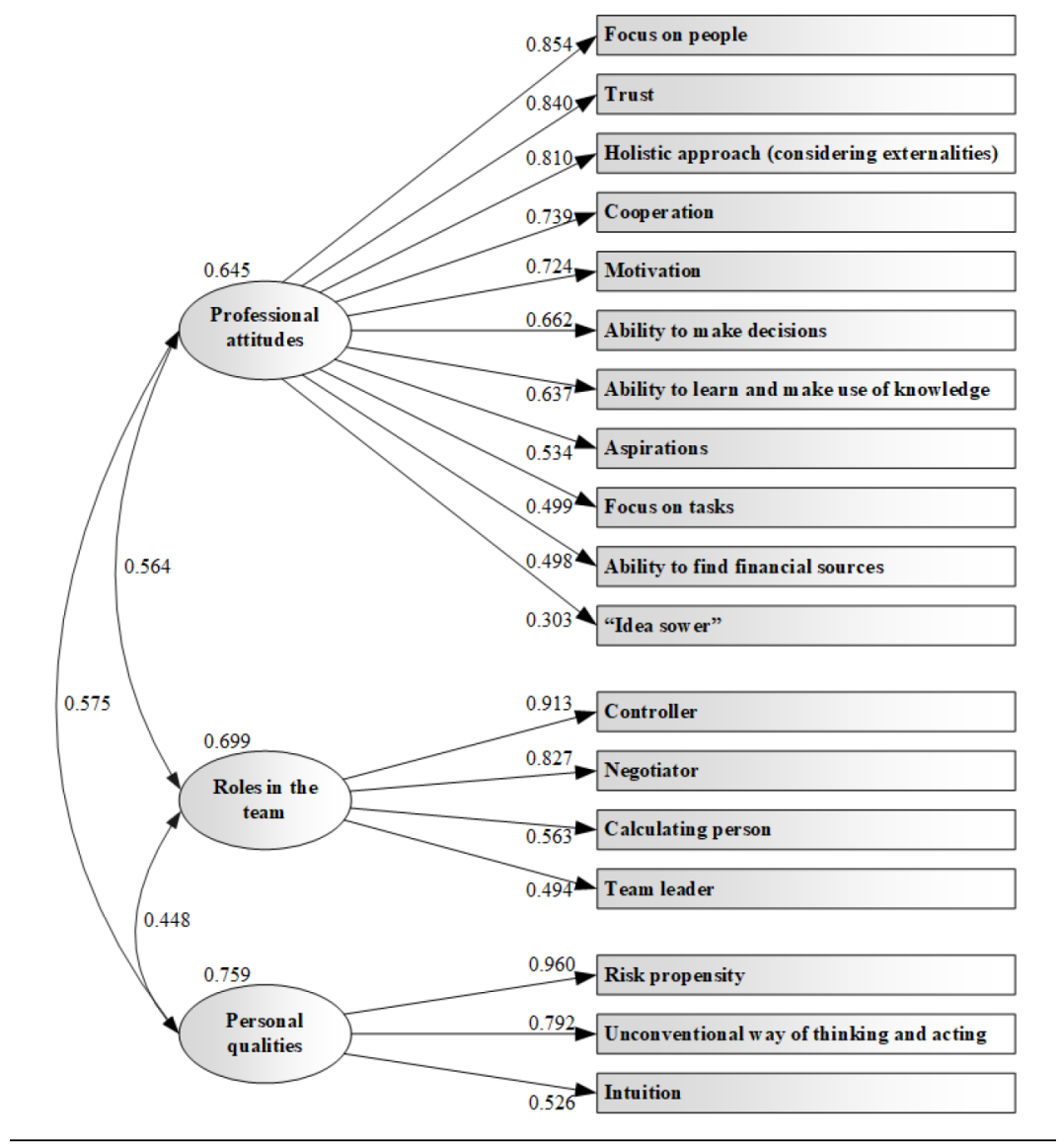

Figure 1. Women's participation model in the innovation process (source: Author's work, with Amos use)

to indicating the verified contents more accurately. The average component loadings allowed the variation explanation in the original data to be preserved, while reflecting the scale of the item (Comrey \& Lee, 1992; Tabachnick \& Fidell, 2001; DiStefano et al., 2009): the professional attitudes component contained 11 variables, with a variance explanation ranked $0.303-$ 0.854; the roles in the team component contained four variables, with a variance explanation ranked 0.494-0.913; and the personal qualities component contained three variables, with a loading accounted at $0.526-0.960$. Table 1 represents the component correlation matrix of women's participation in the innovation process.

The reliability statistics were validated by the Cronbach Alpha Test $(\alpha>0.74)$ (Cronbach, 1951, 1970; Cortina, 1993; Kline, 2000; George \& Mallery, 2003; Cronbach \& Shavelson, 2004; DeVellis, 2012). The test results demonstrated the reliability of the obtained results and supported the interval consistency of the items by justifying their use in a summated scale. It was not possible to obtain a higher value through the removal of a variable in the Cronbach Alpha Test, which signified optimum reliability. 
Table 1. Component correlation matrix of women's participation in the innovation process of companies (source: Author's work, with SPSS use)

\begin{tabular}{|l|c|c|c|}
\hline \multicolumn{1}{|c|}{ Component } & Professional attitudes & Roles in the team & Personal qualities \\
\hline Professional attitudes & 1.000 & - & - \\
\hline Roles in the team & 0.564 & 1.000 & - \\
\hline Personal qualities & 0.575 & 0.448 & 1.000 \\
\hline Extraction Method: Principal Component Analysis. \\
\hline
\end{tabular}

The "professional attitudes" component combined attitudes that could be characterised in two subsets of variables. The first subgroup was characterised by the external attitude of women towards collaborators participating in the innovation process and included: focus on people, trust, holistic approach, and cooperation. The second subgroup exemplified individuality, personal skills, and internal attitude and included: motivation, ability to make decisions, ability to learn and make use of knowledge, ability to find financial sources, aspirations, focus on tasks, and being an "idea sower".

The component of "roles in the team" was characterised by a spectrum of roles, ranging from the most formal (controller) to the most informal (team leader). A symptomatic discrepancy was noteworthy: on the one hand, the variable "trust" had a significant position among women's attitudes in relation to the environment, however, in the "roles in the team" component, the most prominent role of women was as a controller. How the attitude of trust with the role of controller can be reconciled? The informal role of team leader is based on mutual trust, which occurs naturally during teamwork in the innovation process. In this context, the overriding attitude is trust, which promotes the evolution of the role of team leader but does not exclude the role of controller. This combination of attitudes and roles constitutes a new approach to preparing employees for participation in the innovation process. It requires the appropriate preparation, hard and soft, of specific competencies targeting trust, and the roles of controller, and team leader. It requires the ability to act as controller while maintaining trust, which paves the way to building a team leader position.

The final component of "personal qualities" comprises the skills and abilities of women to cope with risks. It contained the vital skill of risk propensity, in which women's participation in the innovation process should be combined with unconventional thinking and acting, and intuition. The attitudes included in this component require a balance of use. One indicator of the area in which a woman moves when taking part in the innovation process, is that of risk propensity: in this context, there is a place for women's intuition, which is a manifestation of unconventional thinking, although it can often indicate the need for unconventional actions.

\subsection{Men participation models in innovation process}

Figure 2 (model 2) presents the values of each variable loading in the designated component. Based on the variables included in the components and their average loadings, the components were: professional attitudes, 0.686; values and behaviours, 0.694; personal qualities, 
0.658; and roles in the team, 0.656 . These four components contain 17 variables out of the 25 variables covered by the research. These also represent a different, and empirically proven, design of the model of male participation in the innovation process within Polish innovative companies. Since these components contain different sets of variables, their names also differ and are more suited to indicating the verified contents more accurately.

The average component loadings allowed the variation explanation in the original data to be preserved, while reflecting the scale: the professional attitudes component contained six variables, with variance explanation ranked $0.537-0.805$; values and behaviours contained four variables, with variance explanation ranked $0.476-0.931$; personal qualities contained three variables, with loading accounted $0.541-0.885$; and roles in the team contained three variables, with loading ranked $0.316-0.859$. Table 2 represents the component correlation matrix of men's participation in the innovation process.

The Cronbach Alpha Test results $(\alpha>0.73)$ showed the reliability of the results obtained and supported the interval consistency of the items, which justified their use in a summated scale.

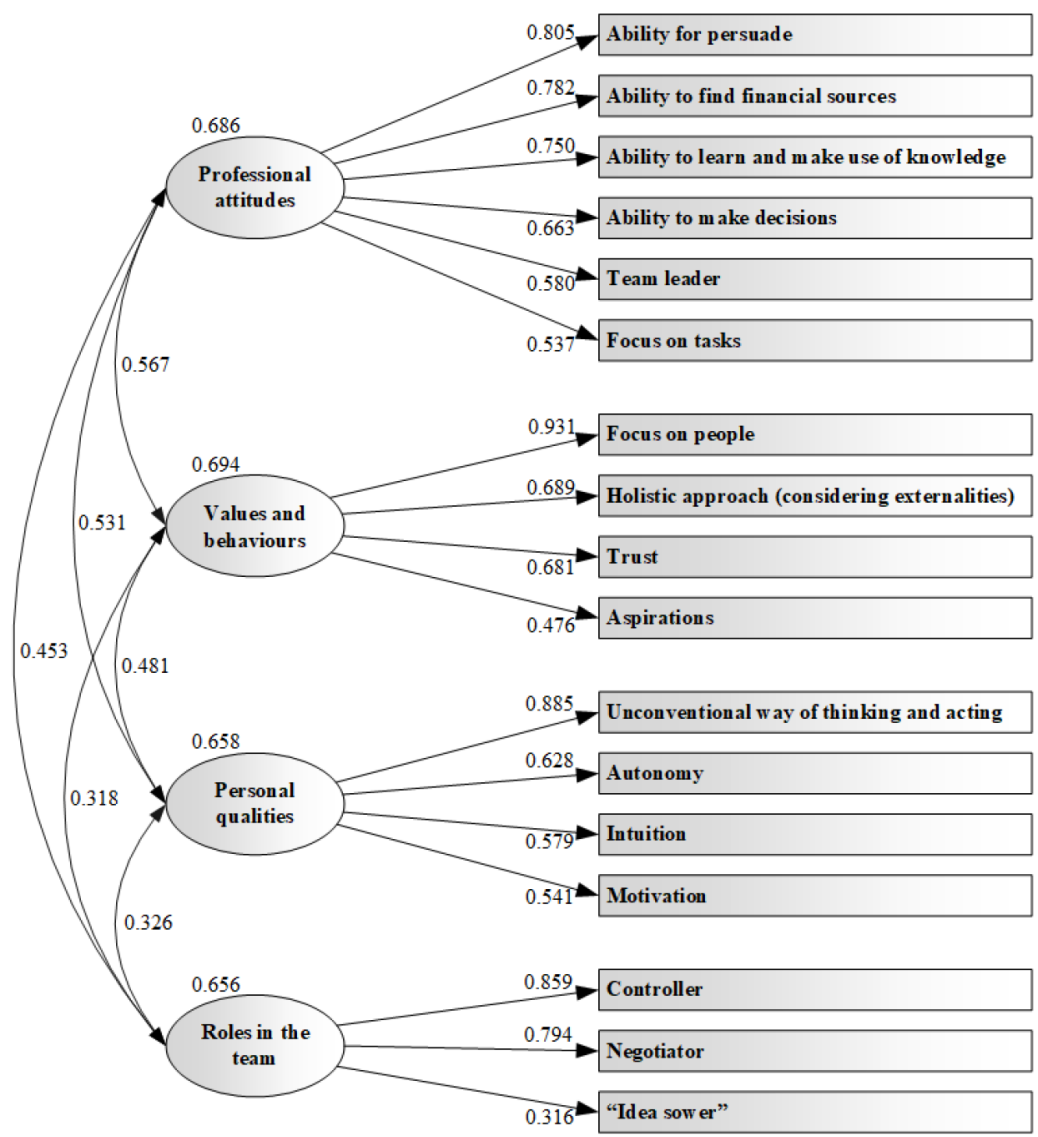

Figure 2. Men's participation model in the innovation process (source: Author's work, with Amos use) 
Table 2. Component correlation matrix of men's participation in the innovation process of companies (source: Author's work, with SPSS use)

\begin{tabular}{|l|c|c|c|c|}
\hline \multicolumn{1}{|c|}{ Component } & $\begin{array}{c}\text { Professional } \\
\text { attitudes }\end{array}$ & $\begin{array}{c}\text { Values and } \\
\text { behaviours }\end{array}$ & Personal qualities & Roles in the team \\
\hline Professional attitude & 1.000 & - & - & - \\
\hline $\begin{array}{l}\text { Values and } \\
\text { behaviours }\end{array}$ & 0.567 & 1.000 & - & - \\
\hline Personal qualities & 0.531 & 0.481 & 1.000 & 1.000 \\
\hline Roles in the team & 0.453 & 0.318 & 0.326 & \\
\hline \multicolumn{4}{|l|}{ Extraction Method: Principal Component Analysis. } \\
\hline
\end{tabular}

The "professional attitudes" component included hard and soft skills: for men, these are the most important determinants of personal conditions in the innovation process. These competencies are intrinsically tied to the performance of the team leader role and the ability to focus on tasks. As such, acting as team leader is combined with a high level of competence. The 'values and behaviours' component comprised variables characterising aspirations and attitudes towards other people participating in the innovation process. In this component, the most important attitude was that of "focus on people", associated with a "holistic approach" and "trust of others". The "personal qualities" component represented individuality and independent thinking during the innovation process. An unconventional way of thinking and acting, linked with an appropriate level of "autonomy" and "motivation", and using "intuition" should be accompanied by the bold actions of men involved in the innovation process. The noteworthy occurrence of "motivation" should be considered, not only as a personal characteristic attitude of men, but also as a feature of the environment in which individual initiative is adequately rewarded. The component of "roles in the team" contained three variables that could characterise the formal role of men in the innovation process. The most important being the "controller", followed by the "negotiator", and then "idea sower". The variable of idea sower was noteworthy and identified with a formal role for many men in this research.

\section{Discussion}

The undertaking of research, management of the innovation process, and commitment of tangible and intangible assets (including the methods of obtaining them) are among the areas of activity that often determine the competitive advantages of a company. Thus, a significant part contains sensitive information, from the decision-making point of view, of the development of a competitive advantage. According to the complexity theory of management, the innovation process is definitively characterised as a complex open system, in which a reductionist approach that intends to define a deterministic path of conduct in the decision process is not feasible (Richardson, 2008). Hence, in the innovation process, there is no one solution as the result of decision-making, which leads to achieving goals in the most effective and efficient way (Espinosa \& Walker, 2017). Decision makers, such as managers and 
team leaders, must specify goals and targets, while allowing teams to use their emergence, self-organisation, and adoption abilities in order to liberate the maximum possibilities and achieve these goals effectively and efficiently.

The creation of such teams requires considerable time; however, the role of decisionmakers in the innovation process is currently substantially different (Sawyer, 2012; D. Cropley \& A. Cropley, 2015). In order to change the nature of the decision-making process, it is necessary to consider additional characteristics of all participants, professionals, and scientific personnel, including gender-related features that indicate the advantages of women and men in some phases of the process. Such features represent business secrets that are not readily communicated outside of the company. Selection of people, based on appropriate education and experience, is openly discussed in the reviewed literature and is always considered when creating project teams. A crucial part of the research study was to identify areas - aside from education, skills and professional experience - that may present new and previously untapped sources of innovation, as a result of differences in the participation of women and men in the innovation process and their influence over decision-making. Both the complexity theory and the literature review lead the conclusion that the studied object is exceptionally diverse, specifically, research conducted by Nählinder, Tillmar and Wigren (2015). This research covered the three gender dimensions in innovation and gender-bias and explored ways to reduce them (Nählinder et al., 2015). In Blake and Hanson's (2005) research, they argued that the social and geographical contexts of an innovation are elementary to the identification gender role; thus, research conducted in various conditions and countries, such as those presented in this article, is another step in the direction of a deeper understanding of the participation of women and men in the innovation process.

\section{Conclusions}

This study aimed to capture the essential characteristics, attitudes, and behaviours - both common and different - among women and men involved in innovation processes within pioneering companies. The application of PCA with the Promax rotation method allowed for separate sets of variables (and their maximum values) to be identified, which formed the descriptors for women and men participating in the innovation process of pioneering companies in Poland. The authors of this study are aware that even a broad study of the examined subject does not allow for an exhaustive description. Considering the nature of the examined subject, and the perspective of team management, the significant number of variables represents enough statistical accuracy. From this standpoint, the obtained results are considered significant.

The study identified a statistically significant set of 18 variables for women that were grouped into three components, while 17 statistically significant variables, grouped into four components, were identified for men. The applied PCA method facilitated their identification, and the models presented here are an attempt to develop a holistic approach to the complex issue of gender participation in the innovation process in pioneering Polish companies. In the female participation model, the prevailing variables characterising attitudes were those external to colleagues, formal and informal roles, and the coping skills of women 
in situations of higher risk which are undoubtedly related to innovation. The male participation model in the innovation process emphasised competencies that were related to acting as an informal team leader. It also stressed the importance of unconventional thinking and behaviour, which is subject to a degree of autonomy and motivation. Finally, this model emphasised formal roles, among which "controller" and "negotiator" were the leading roles in the desired innovation process phases.

The main difference found in the participation models related to taking, and dealing with, risks. In the female model, this issue was statistically significant, while in the male model it was almost absent. This was further confirmed by the variables removed from the analysis. For men, variables such as a tendency to take risks and a calculating persona did not constitute statistically significant traits, attitudes, or behaviours in the innovation process. However, in both models, variables such as competition, workload, compliance to rules and regulations and perceptiveness were considered statistically insignificant in the innovation process. These variables appear to confirm that the participation of women and men should not be based on competition and refer to the identification of the need for cooperation within the context of the work performed. The variables also indicated that compliance with rules and regulations did not play a significant role and that it is associated with a need to look for the best solutions during the innovation process. This is something that is intrinsically linked to unconventional thinking and acting, rather than to compliance with rules and regulations. This study's constructed model, consisting of two data sets separately compiled for women and men, also assisted in the identification of biases or prejudices; the results indicate that in the environment of Polish innovative enterprises, there is no bias, but rather a mutual misunderstanding between the approaches of women and men in innovation development.

The presented models unambiguously demonstrate that both the hypotheses presented in this article are accurate: male and female participation in the innovation process is different, thus, the process of innovation is not gender neutral. However, the profiles of women and men in the innovation process are described using specific characteristics, behaviours, skills and roles. Thus, the participation of women and men in the various phases of the innovation process is different. This addresses the research question of whether, in pioneering companies in Poland, the participation of women and men in the innovation process is different. The models represent and describe this difference. Compared to men, women have significantly higher levels of trust, focus on people more, risk propensity, holistic approach, and make decisions in the innovation process. Men bring significantly greater levels of concentration on competences, focus more on their tasks, and are more likely to show unconventional ways of thinking and acting. The combination of risk propensity, people-centric focus, and higher levels of trust utilised by women, and the unconventional ways of thinking and acting utilised by men, when working together, may be a source of rapid development and cooperation hitherto unused in the innovation process. The presented conclusions form a set of novel and advantageous guidelines for application in the decision-making process as well as methods that better utilise the skills of both women and men in the innovation process more effectively.

The implications for researchers and practitioners are that women and men both play 
critical and effective roles in different phases of the innovation process. Thus, their level of participation in this process is not only different but is something that should be respected by managers and team leaders during the decision-making process. The results demonstrate how gender should be carefully considered when managers are building efficient and effective teams for the different phases of the innovation process, and when selecting candidates to fulfil the required roles. Each phase is characterised by different requirements and specifications, therefore, the participation models for women and men should be considered when building teams for each phase. For researchers, these results could bring new ideas of how to develop research techniques - in order to better explore the roles of women and men - and how to apply future results to achieve more effective innovation processes.

The presented research results are not free of limitations. The results were obtained based on the experience of women and men involved in the various innovation processes undertaken in pioneering companies in Poland. The subject of research into gender and innovation is dependent on both the geographical and social environments. Thus, the results of this report are most useful in Poland and the countries of Eastern Europe. Another limitation is that the research subject may change, thus, it is reasonable to repeat the research regularly.

Empirically verified variables in each model extend area of the examined object to new and not often taken under research personal characteristics, attitudes and behaviours with regard to gender related issues in innovation process. It could be continued in the future to get more accurate and detailed picture of the studied object. Creation effective teams is not easy process and require a considerable amount of time. Similarly obtain knowledge, skills and abilities by employees, required by the sustain innovation development is the long term and continuous process. Thus the results presented in this text are still valid today. Presented models can be helpful for managers who need to create more effective teams in the innovation process and in their decisions want to take into account not only education or experience skills, which is always done, but also personal characteristics, attitudes and behaviours. The presented models can also be developed in the future. Variables included in models compose a specific set of factors, which help in decision process. However, it should be noted that the process itself worked differently in different companies. Therefore, it is not a completely repeatable examined object. Despite common steps, characteristics, and purposes, it contains a high level of uniqueness. Nevertheless, the systematic research in the area begun here may uncover a deeper understanding of the roles of men and women in the future, which in turn might make it possible to more accurately translate them in order to accelerate innovative development.

\section{Acknowledgements}

Not applicable.

\section{Funding}

Not applicable. 


\section{Author contributions}

The work contribution of each author: Ewa Okoń-Horodyńska, Anna Zachorowska-Mazurkiewicz, Rafał Wisła and Tomasz Sierotowicz is the same and even. Authors worked together on each part of this text.

\section{Disclosure statement}

The authors of this article declare that they do not have any competing financial, professional, or personal interests from other parties.

\section{References}

Abels, G. (2012). Research by, for and about women: Gendering science and research policy. In G. Abels \& J. M. Mushaben (Eds.), Gendering European Union. New approaches to old democratic deficits (pp. 187-207). Palgrave Macmillan. https://doi.org/10.1057/9780230353299_10

Abukhait, R., Bani-Melhem, S., \& Zeffane, R. (2019). Empowerment, knowledge sharing and innovative behaviours: Exploring gender differences. International Journal of Innovation Management, 23(1), 1950006-1-1950006-28. https://doi.org/10.1142/S1363919619500063

Acklin, C. (2010). Design-driven innovation process model. Design Management Journal, 5(1), 50-60. https://doi.org/10.1111/j.1948-7177.2010.00013.x

Alsos, G. A., Ljunggren, E., \& Hytti, U. (2013). Gender and innovation: State of the art and a research agenda. International Journal of Gender and Entrepreneurship, 5(3), 236-256. https://doi.org/10.1108/IJGE-06-2013-0049

Alvarez, J., Martinez-Roman, R., Munoz-Mari, J., \& Camps-Valls, G. (2018). Digital signal processing with Kernel methods. Willey \& Sons.

Amabile, T. M., Conti, R., Coon, H., Lazenby, J., \& Herron, M. (1996). Assessing the work environment for creativity. Academy of Management Journal, 39(5), 1154-1184. https://doi.org/10.2307/256995

Apesteguia, J., Azmat, G., \& Iriberri, N. (2012). The impact of gender composition on team performance and decision-making: Evidence from the field. Management Science, 58(1), 78-93. https://doi.org/10.1287/mnsc.1110.1348

Bartlett, M. S. (1950). Tests of significance in factor analysis. British Journal of Psychology, 3(1), 77-85. https://doi.org/10.1111/j.2044-8317.1950.tb00285.x

Blake, M. K., \& Hanson, S. (2005). Rethinking innovation: context and gender. Environment and Planning $A, 37,681-701$. https://doi.org/10.1068/a3710

Brieger, S., \& Francoeur, C. (2019). Empowering women: The role of emancipative forces in board gender diversity. Journal of Business Ethics, 155(2), 495-511. https://doi.org/10.1007/s10551-017-3489-3

Carrasco, I. (2014). Gender gap in innovation: an institutionalist explanation. Management Decision, 52(2), 410-424. https://doi.org/10.1108/MD-07-2012-0533

Cattell, R. B. (1966). The scree test for the number of factors. Multivariate Behavioral Research, 1(2), 245-276. https://doi.org/10.1207/s15327906mbr0102_10

Cattell, R. B. (1978). The scientific use of factor analysis. Plenum.

Comrey, A. L., \& Lee, H. B. (1992). A first course in factor analysis ( $2^{\text {nd }}$ ed.). Lawrence Erlbaum Associates, Inc.

Cooper, R. (2012). The gender gap in union leadership in Australia: A qualitative study. Journal of Industrial Relations, 54(2), 131-146. https://doi.org/10.1177/0022185612437836 
Cortina, J. M. (1993). What is coefficient alpha? An examination of theory and applications. Journal of Applied Psychology, 78(1), 98-104. https://doi.org/10.1037/0021-9010.78.1.98

Costello, A., \& Osborne, J. W. (2005). Best practices in exploratory factor analysis: Four recommendations for getting the most from your analysis. Practical assessment. Research \& Evaluation, 10(7), $1-9$.

Cramer, D. (1998). Fundamental statistics for social research. Routledge.

Cramer, D., \& Howitt, D. (2004). The SAGE dictionary of statistics. SAGE. https://doi.org/10.4135/9780857020123

Cronbach, L. J. (1951). Coefficient alpha and the internal structure of tests. Psychometrika, 16, 297-334. https://doi.org/10.1007/BF02310555

Cronbach, L. J. (1970). Essentials of psychological testing. Harper \& Row.

Cronbach, L. J., \& Shavelson, R. J. (2004). My current thoughts on coefficient alpha and successor procedures. Educational and Psychological Measurement, 64(3), 391-418. https://doi.org/10.1177/0013164404266386

Cropley, D., \& Cropley, A. (2015). The psychology of innovation in organizations. Cambridge University Press. https://doi.org/10.1017/CBO9781316104811

Danilda, I., \& Thorslund, J. G. (Eds.). (2011). Innovation and Gender. Stockholm, VInnoVA-Verket för Innovationssystem/Swedish Governmental Agency for Innovation System.

Demos, V., \& Segal, M. (Eds.). (2017). Gender panic, gender policy (advances in gender research). Emerald Publishing. https://doi.org/10.1108/S1529-2126201724

DeVellis, R. F. (2012). Scale development: Theory and applications. Sage.

Dien, J., Beal, D. J., \& Berg, P. (2005). Optimizing principal components analysis of event-related potentials: Matrix type, factor loading weighting, extraction, and rotations. Clin Neurophysiol, 116(8), 1808-1825. https://doi.org/10.1016/j.clinph.2004.11.025

DiStefano, Ch., Zhu, M., \& Mîndrilă, D. (2009). Understanding and using factor scores: Considerations for the applied researcher. Practical Assessment, Research \& Evaluation, 14(20), 1-11.

Doane, D. P., \& Seward, L. E. (2011). Measuring skewness. Journal of Statistics Education, 19(2), 1-18. https://doi.org/10.1080/10691898.2011.11889611

Du Vall, M., \& Majorek, M. (2015). Taking gender seriously Present trends and recommendations for scientific environment. In E. Okoń-Hoodyńska \& A. Zachorowska-Mazurkiewicz (Eds.), Statistical profiles of women's and men's status in the economy, science and society (pp. 47-66). Jagiellonian University Press.

Dufwenberg, M., \& Muren, A. (2006). Gender composition in teams. Journal of Economic Behavior and Organization, 61(1), 50-54. https://doi.org/10.1016/j.jebo.2005.01.002

Dylag, A., \& Szafranski, M. (2015). Contemporary value profiles of women and men - Polish pilot survey. In E. Okoń-Hoodyńska \& A. Zachorowska-Mazurkiewicz (Eds.), Statistical profiles of women's and men's status in the economy, science and society (pp. 145-164). Jagiellonian University Press.

Dziuban, C. D., \& Shirkey, E. C. (1974). When is a correlation matrix appropriate for factor analysis? Psychological Bulletin, 81, 358-361. https://doi.org/10.1037/h0036316

Espinosa, A., \& Walker, J. (2017). A complexity approach to sustainability. Theory and practice. World Scientific Publishing Europe Ltd. https://doi.org/10.1142/q0060

Field, A. (2012). Discovering statistics using IBM SPSS statistics. SAGE.

Fogelberg, E. A. (2014). A gender perspective as a trigger and facilitator of innovation. International Journal of Gender and Entrepreneurship, 6(2), 163-180. https://doi.org/10.1108/IJGE-09-2012-0045

Foss, L., Woll, K., \& Moilanen, M. (2013). Creativity and implementations of new ideas: Do organizational structure, work environment and gender matter? International Journal of Gender and Entrepreneurship, 5(3), 298-322. https://doi.org/10.1108/IJGE-09-2012-0049 
Frankl, V. (1967). Psychotherapy and Existentialism. Washington Square Press. https://doi.org/10.1037/h0087982

Frankl, V. (1969). The will to meaning. Meridian Books.

Geissdoerfer, M., Bocken, N., \& Hultink, E. (2016). Design thinking to enhance the sustainable business modelling process - A workshop based on a value mapping process. Journal of Cleaner Production, 135, 1-31. https://doi.org/10.1016/j.jclepro.2016.07.020

George, D., \& Mallery, P. (2003). SPSS for Windows step by step: A simple guide and reference. Allyn \& Bacon.

Ghaye, T., \& Gunnarsson, E. (2009). Creating cultures of appreciation, organisational innovation through employee well-being. In M. Döös \& L. Wilhelmson (Eds.), Organising work for innovation and growth (pp. 23-38). Vinnova.

Hair, J. F. Jr., Black, W. C., Babin, B. J., \& Anderson. R. E. (2014). Multivariate data analysis. Pearson.

Henson, R. K., \& Roberts, J. K. (2006). Use of exploratory factor analysis in published research: Common errors and some comment on improved practice. Educational and Psychological Measurement, 66, 393-416. https://doi.org/10.1177/0013164405282485

Hunt, J., Herman, H., \& Munroe, D. J. (2013). Why are women underrepresented amongst patentees? Research Policy, 42, 831-843. https://doi.org/10.1016/j.respol.2012.11.004

Kaiser, H. F. (1960). The application of electronic computers to factor analysis. Educational and Psychological Measurement, 20, 141-151. https://doi.org/10.1177/001316446002000116

Kaiser, H. F. (1970). A second generation little jiffy. Psychometrika, 35(4), 401-415. https://doi.org/10.1007/BF02291817

Kaiser, H. F., \& Rice, J. (1974). Little Jiffy, Mark IV. Educational and Psychological Measurement, 34(1), 111-117. https://doi.org/10.1177/001316447403400115

Kim, H.-J., (2008). Common factor analysis versus principal component analysis: Choice for symptom cluster research. Asian Nursing Research, 2(1), 17-24.

https://doi.org/10.1016/S1976-1317(08)60025-0

Kline, P. (1994). An easy guide to factor analysis. SAGE.

Kline, P. (2000). The handbook of psychological testing. Routledge.

Kopycinska, D. (2015). The professional situation of women and men in Poland - declarations and reality. In E. Okoń-Hoodyńska, \& A. Zachorowska-Mazurkiewicz (Eds.), Statistical profiles of women's and men's status in the economy, science and society (pp. 91-106). Jagiellonian University Press.

Kunze, A., \& Miller, A. R. (2017). Women helping women? Evidence from private sector data on workplace hierarchies. Review of Economics and Statistics, 99(5), 769-775. https://doi.org/10.1162/REST_a_00668

Larsen, R., \& Warne, R. T. (2010). Estimating confidence intervals for eigenvalues in exploratory factor analysis. Behavior Research Methods, 42, 871-876. https://doi.org/10.3758/BRM.42.3.871

Lindberg, M., \& Schiffbaenker, H. (2013). Gender and innovation. In E. G. Carayannis (Ed.), Encyclopedia of creativity, invention, innovation and entrepreneurship (pp.782-789). Springer. https://doi.org/10.1007/978-1-4614-3858-8_454

Lindberg, M., Danilda, I., \& Torstensson, B. M. (2012). Women resource centers - a creative knowledge environment of quadruple helix. Journal of the Knowledge Economy, 3(1), 36-52. https://doi.org/10.1007/s13132-011-0053-8

MacCallum, R. C., Widaman, K. F., Zhang, S., \& Hong, S. (1999). Sample size in factor analysis. Psychological Methods, 4(1), 84-99. https://doi.org/10.1037/1082-989X.4.1.84

Messerschmitt, W., Messner, A., Connell, R., \& Martin, Y. (Eds.). (2018). Gender Reckonings: New social theory and research. NYU Press. https://doi.org/10.2307/j.ctt1pwtb3r 
Nählinder, J., Tillmar, M., \& Wigren, C. (2015). Towards a gender-aware understanding of innovation, a three-dimensional route. International Journal of Gender and Entrepreneurship, 7(1), 66-86. https://doi.org/10.1108/IJGE-09-2012-0051

Norman, G. R., \& Streiner, D. L., (2003). Statistics. PDQ.

O'Connor, B. P. (2000). SPSS and SAS programs for determining the number of components using parallel analysis and Velicer's MAP test. Behavior Research Methods, Instrumentation, and Computers, 32, 396-402. https://doi.org/10.3758/BF03200807

OECD. (2005). Oslo manual: Guidelines for collecting and interpreting innovation data. OECD Publisher.

Østergaard, C. R., Timmermans. B., \& Kristinsson, K. (2011). Does a different view create something new? The effect of employee diversity on innovation. Research Policy, 40(3), 500-510. https://doi.org/10.1016/j.respol.2010.11.004

Pecis, L. (2016). Doing and undoing gender in innovation. Femininities and masculinities in innovation processes. Human Relations, 69(11), 2117-2140. https://doi.org/10.1177/0018726716634445

Pett, M. A., Lackey, N. R., \& Sullivan, J. J. (2003). Making sense of factor analysis: The use of factor analysis for instrument development in health care research. SAGE. https://doi.org/10.4135/9781412984898

Pettersson, K. (2007). Men and male as the norm? A gender perspective on innovation policies in Denmark, Finland and Sweden. Nordregio.

Poutanen, S., \& Kovalainen, A. (2013). Gendering innovation process in an industrial plant, revisiting tokenism, gender and innovation. International Journal of Gender and Entrepreneurship, 5(3), 257-274. https://doi.org/10.1108/IJGE-09-2012-0054

Ranga, M., \& Etzkowitz, H. (2010). Athena in the world of techne: The gender dimension of technology, innovation and entrepreneurship. Journal of Technology, Management \& Innovation, 5(1), 1-12. https://doi.org/10.4067/S0718-27242010000100001

Razali, N. M., \& Wah, Y. B. (2011). Power comparisons of Shapiro-Wilk, Kolomogorov-Smirnov, Lilliefors and Anderson-Darling tests. Journal of Statistical Modeling and Analytics, 2(1), 21-33.

Reutzel, C. R., Collins, J. D., \& Belsito, C. A. (2018). Leader gender and firm investment in innovation. Gender in Management, 33(6), 430-450. https://doi.org/10.1108/GM-05-2017-0066

Richardson, K. (2008). Managing complex organizations: Complexity thinking and the science and art of management. E:CO, 10(2), 13-26.

Rothwell, R. (1994). Industrial innovation: Success, strategy, trends. In R. Rothwell \& M. Dogson (Eds.), The Handbook of industrial innovation, s. 41. Edward Elgar Publishing.

Salk, R. H., Hyde, J. S., \& Abramson, L.Y. (2017). Gender differences in depression in representative national samples: Meta-analyses of diagnoses and symptoms. Psychological Bulletin, 143(8), 783-822. https://doi.org/10.1037/bul0000102

Sawyer, K. (2012). Explaining creativity: The science of human innovation. Oxford University press.

Schumpeter, J. A. (1934). The theory of economic development. Oxford University Press.

Shapiro, S. S., \& Wilk, M. B. (1965). An analysis of variance test for normality (Complete samples). Biometrika, 52(3/4), 591-611. https://doi.org/10.1093/biomet/52.3-4.591

Sierotowicz, T. (2015). Patent activity as an effect of the research and development of the business enterprise sectors in the countries of the European Union. Journal of International Studies, 8(2), 31-43. https://doi.org/10.14254/2071-8330.2015/8-2/9

Skarzynski, P., \& Gibson, R. (2013). Innovation to the core: A blueprint for transforming the way your company innovates. Harvard Business Press.

Smith, S. (2013). Digital signal processing. Elsevier Science. 
Snook, S. C., \& Gorsuch, R. L. (1989). Principal component analysis versus common factor analysis: A Monte Carlo study. Psychological Bulletin, 106, 148-154. https://doi.org/10.1037/0033-2909.106.1.148

Streiner, D. L. (2003). Starting at the beginning: An introduction to coefficient alpha and internal consistency. Journal of Personality Assessment, 80, 99-103. https://doi.org/10.1207/S15327752JPA8001_18

Streiner, D. L., Norman, G. R., \& Cairney, J. (2015). Health measurement scales: A practical guide to their development and use. Oxford University Press. https://doi.org/10.1093/med/9780199685219.001.0001

Tabachnick, B. G., \& Fidell, L. S. (2001). Using multivariate statistics ( $4^{\text {th }}$ ed.). Allyn \& Bacon.

Tidd, J., \& Bessant, J. (2017). Managing innovation: Integrating technological, market and organizational change. John Willey \& Soons.

Twiss, B. C. (1995). Managing technological innovation. Pitman Publishing.

Ye, D., Gudko, B., \& Fangsheng, D. (2019). The direct and indirect impact of gender diversity in new venture teams on innovation performance. Entrepreneurship Theory and Practice, 43(3), 505-528. https://doi.org/10.1177/1042258718807696

Zachorowska-Mazurkiewicz, A. (2016). Praca kobiet. Perspektywa ekonomii głównego nurtu i ekonomii feministycznej. Jagiellonian University Press.

Zinbarg, R., Yovel, I., Revelle, W., \& McDonlad, R. (2006). Estimating generalizability to a latent variable common to all of a scale's indicators: A comparison of estimators for $\omega_{\mathrm{h}}$. Applied Psychological Measurement, 30(2), 121-144. https://doi.org/10.1177/0146621605278814 